\title{
Advanced Machining of Al Alloy Based Metal Matrix Composites
}

\author{
S. Suresh Kumar, M. Uthayakumar, S. Thirumalai Kumaran, Mustafa Aslan, K. Vinoth Babu
}

\begin{abstract}
Machining of engineering materials becomes inevitable nowadays as the making of products having near net shape and size to meet its requirement is more important. The modern industrial need emerges the thrust for new materials which could satisfy the different performance characteristics. Among all, Metal Matrix Composites (MMCs) plays a foremost role in the engineering application for the replacement of various materials. Most importantly Al alloy based MMCs are widely used materials as it has more strength to weight ratio with attractive characteristics. However, machining of such a material to form required shape is not efficient through conventional machining processes. This article presents the detailed report on non conventional machining of Al alloy based MMCs.
\end{abstract}

Keywords: machining, Al composites, EDM.

\section{INTRODUCTION}

$\mathrm{E}_{\text {ven though, the conventional methods of machining }}$ MMCs are suitable with some deficit, recently researchers have enlightened their focus on non conventional methods of machining the composite materials. The modern techniques of machining includes Electrical Discharge Machining (EDM), Abrasive Water Jet Machining (AWJM), laser cutting, Electro Chemical Machining (ECM) [1]. The quality of the finished surface and the dimensional inaccuracy are the major problem noticed with non-traditional techniques [2]. However, the economic aspects of modern machining techniques for composites are also been addressed by the researchers nowadays [3].

\section{AWJM PROCESS}

AWJM process is a mechanical energy based machining technique and the mechanism of metal removal is abrasion action which is used by many researchers. Muller et al.

Revised Manuscript Received on December 29, 2019.

S. Suresh Kumar*, Faculty of Mechanical Engineering, Kalasalingam Academy of Research and Education, Srivilliputhur, India. Email: sureshme48@gmail.com

M. Uthayakumar, Faculty of Mechanical Engineering, Kalasalingam Academy of Research and Education, Srivilliputhur, India. Email: uthaykumar@gmail.com

S. Thirumalai Kumaran, Faculty of Mechanical Engineering, Kalasalingam Academy of Research and Education, Srivilliputhur, India. Email: thirumalaikumaran@yahoo.com

Mustafa Aslan, Dartment of Metallurgy and Materials Engineering, Karadeniz Technical University, Trabzon, Turkey. Email: maslan@ktu.edu.tr

K. Vinoth Babu, Faculty of Mechanical Engineering, Sri Indu College of Engineering \& Technology, Hyderabad, India. Email: vinothbabukr@gmail.com concluded that AWJM process is not making any thermal damages to the composite materials [4]. Srinivas and Rameshbabu have carried out machining study using AWJM with two abrasive particles having different particulate size. The purpose of the study is to enhance the depth of cut produced by the particles at varying machining condition on the $\mathrm{SiC}$ reinforced $\mathrm{Al}$ alloy fabricated through stir casting process. The result shows that particle of mesh size 80 produces higher depth of cut and $\mathrm{SiC}$ particles passes to maximum depth as it is light and more number of particles occupied for cutting [5]. In the similar research work, the lesser depth was achieved with MMC compared to unreinforced alloy because of enhanced mechanical properties of composite materials [6]. Muller and Monaghan examined the machining aspects of MMCs through AWJM, EDM and laser based cutting processes. They have concluded that AWJM gives the faster cutting than EDM and laser cutting process [7]. Ramulu et al. have done an experimental analysis on the $\mathrm{Al}$ alloy and $\mathrm{SiC}$ reinforced $\mathrm{Al}$ alloy based MMC with varying impact angle. The results show that when impact angle increases, the erosion rate of the composite material also increases at steady flow rate of abrasive particles. However, the metal removal is less in the case of MMC than Alloy material [8]. Kumar and Kumaresan have studied the machinability characteristics of $\mathrm{SiC}$ reinforced $\mathrm{Al}$ MMC prepared through stir casting route. They have analyzed the effect of water pressure, traverse speed and standoff distance with an aim to improve the surface finish. They concluded that the traverse speed is the influencing variable on changing surface finish of the composite material subsequently pressure and distance [9].

\section{EDM AND WEDM PROCESS}

Most of the researchers done EDM process on $\mathrm{Al}$ based MMCs with varying reinforcement so as to identify the affect of machining conditions on machinability characteristics. Hung et al. have studied the viability of machining $\mathrm{Al}$ composite reinforcing with $\mathrm{SiC}$ through EDM. The results revealed that inclusion of $\mathrm{SiC}$ particulates protects the matrix and hence metal removal is reduced [210]. Later, Karthikeyan et al. studied influence of SiC content, pulse current and time on metal removal, surface finish. The analysis shows that the presence of $\mathrm{SiC}$ greatly influenced on the characteristics. Moreover, increased $\mathrm{SiC}$ content and pulse current increases both material removal and tool wear and lowers the finish [11]. P. Narender Singh et al. have worked identifying the 
machinability characteristics of Al-10\% SiCp MMC through EDM process [12].

The goal of this research work is to determine the impact of variables such as pulse duration, current and flushing pressure on characteristics like surface finish, tool wear and metal removal. They have concluded that higher current and duration of spark removes more quantum of materials from the composite where as it increases the tool wear and lowers the machined surface quality. Akshay Dvivedi et al. have done an investigation on machinability of $\mathrm{SiC}$ reinforced $\mathrm{Al}$ alloy based MMC prepared through stir-squeeze-quench casting process. The optimal conditions of machining parameters were found which exhibits the maximum metal removal with tolerable tool wear and accuracy in dimension. Moreover, an increase in the cutting condition results in reduced metal removal and also higher electrode wear [13].

On the other hand, Yan and Wang examined the Al2O3 reinforced $\mathrm{Al}$ alloy based composite machined through EDM having tube electrode [14]. They proposed that this composite is suitable for EDM drilling process compared to other machining techniques. The unconventional machining techniques such as laser machining, water jet and wire EDM are applicable for only linear cutting [15]. Che Wang and Biing Yan investigated the feasibility of making a blind hole on alumina reinforced $\mathrm{Al}$ composites using rotary EDM process. [15]. The drilling of blind-hole is feasible on the MMC and noteworthy point is significance of the electrical parameters are more than that of other parameters. The surface finish and material removal are mostly influenced by polarity.

Later, researchers have introduced some new idea of adding the powder into the dielectric medium during the EDM process which enhances the machinability characteristics. Kansal et al. analyzed the machinability of $\mathrm{Al}$ matrix reinforced with $\mathrm{SiC}$ particles by adding the Aluminium powder in the dielectric medium. The influence of variables on the machining performances were identified and also compared with the previously done research work [16]. Recently a comparison study was reported on EDM process on Alumina reinforced Al based MMC fabricated through stir casting route. The plain and silicon carbide powder mixed dielectric were used for an experimental work and the results of the studies were observed. The examination shows that the inclusion of powder shows better performance. Moreover, the particle size and concentration followed by current are the influencing parameters on affecting the surface texture of the machined composite materials [17]. The recent research work attempted to find the machinability behaviour of B4C and glass reinforced $\mathrm{Al}-\mathrm{SiC}$ hybrid composites. The results revealed that prolong of electrical spark is required for removing the hard particles. The presence of recast layer is observed on both the composites [18].

Among the various available machining techniques, wire WEDM is believed as an efficient and inexpensive process for machining composites [19]. However, limited work was carried out on WEDM of MMC [20-22]. Rozenek et al. have examined the influence of WEDM variables on surface finish

and feed rate while machining $\mathrm{SiC}$ reinforced $\mathrm{Al}$ alloy based metal matrix composite [23]. The increased current, pulse duration and discharge energy increases the feed rate and lowers the finish. Yan et al. [24] have examined the WEDM performance during the machining of alumina reinforced $\mathrm{Al}$ alloy based MMCs. They have observed the wire breakage during cutting process and also concluded that the presence of ceramic particles in higher concentration makes this happen in WEDM process. Manna and Bhattacharyya studied the affect of WEDM variables on the surface quality of $\mathrm{Al}$ composite material. Gap voltage is found to be most influencing parameter followed by pulse duration. Moreover, feed rate and wire tension are the significant factor affects the surface finish of the machined section [25]. The affect of pulse current and pulse time on metal removal of $\mathrm{Al}$ alloy and particle reinforced MMC are as shown in Figure 1 [26].

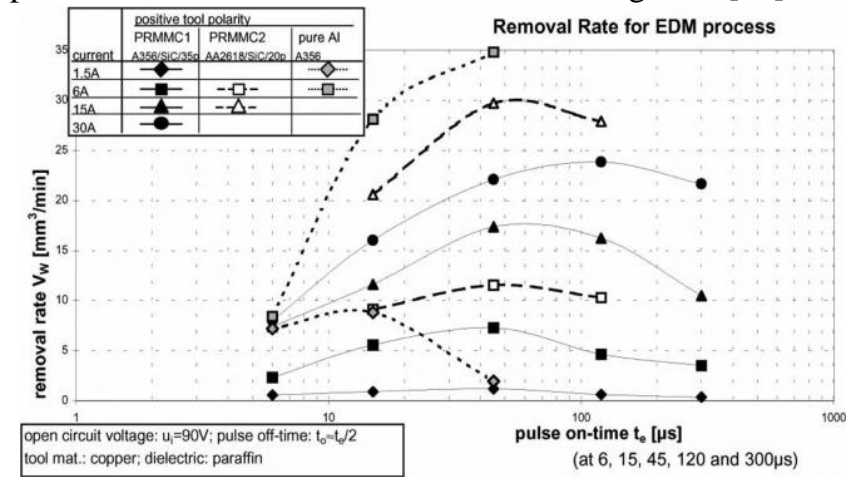

Fig. 1. Material removal rate of MMC and alloy [26].

The most of the research work in electrical discharge energy based was carried out on die-sinking type of EDM process only which is shown in Figure 2 [27]

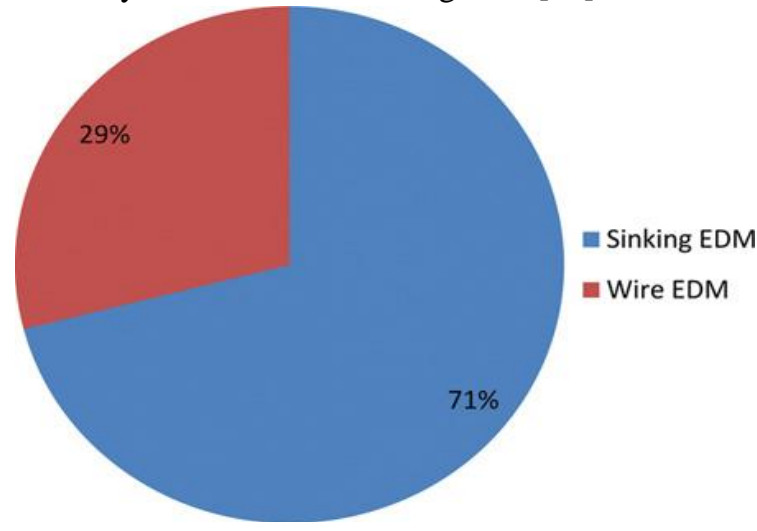

Fig. 2. Research work done on EDM process [27]

\section{ELECTRO CHEMICAL MACHINING (ECM) PROCESS}

ECM is a cost effective and efficient techniques used for the manufacturing the hip-joint implants, turbine blades, rifle bores, micro-components. ECM produces quality products made from composites [28]. In addition, ECM is used advanced machining to produce complex shaped items and electrically conducting material and also difficult to cut materials [29]. The experimental study to evaluate the material 
removal rate at varying current intensities for $\mathrm{Al}$ material using ECM process was done [30]. The experimental finding revealed that the increased current density increases the metal removal, tool wear and over cut of the composites [31-32].

Chenthil Jegan et al. have analyzed the performance of $\mathrm{Al}$ alloy reinforced with SiC MMC using ECM process. The experimental results reveals that the current, voltage and feed rate are directly influences the metal removal. The surface finish is influenced by current, gap and feed rate [33].

Figure 3 illustrates the working Electro Chemical Discharge Machining (ECDG) process suitable for machining non-conductive nature materials and also difficult to cut materials such as composite, ceramics and glass [34-35]. However, the research work in the field of ECDM is initial stage only [36].

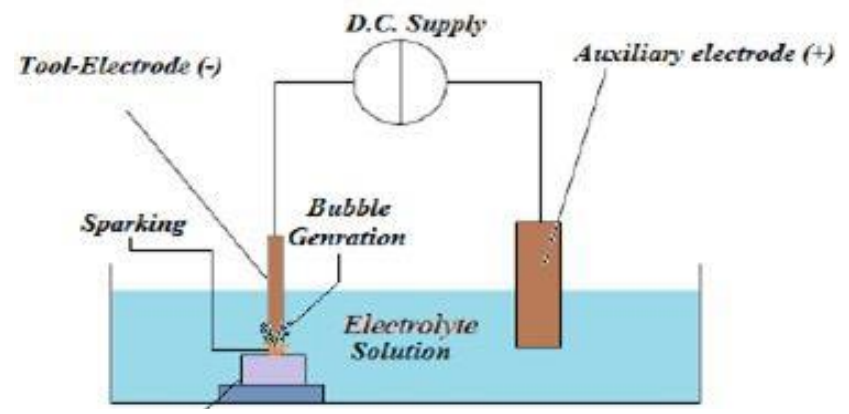

Fig. 3. Working of ECDM process [35]

Figure 4 explicates the combined phenomena of both spark erosion and etching through electro chemical is the mechanism of ECDM process [37]. During EDM, the surface gets damaged and ECM process removes the material by chemical dissolution results in formation of smooth surface. Hence, ECDM end up with better surface finish as it combines the action of both process [38].

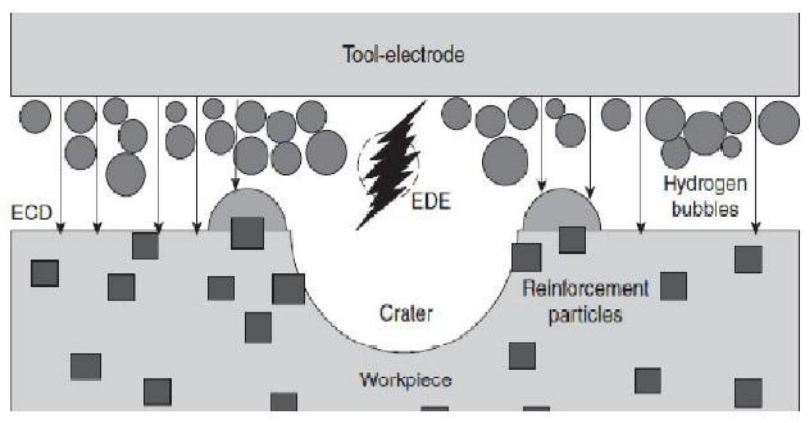

Fig. 4. Schematic of combined mechanism of metal removal [39]

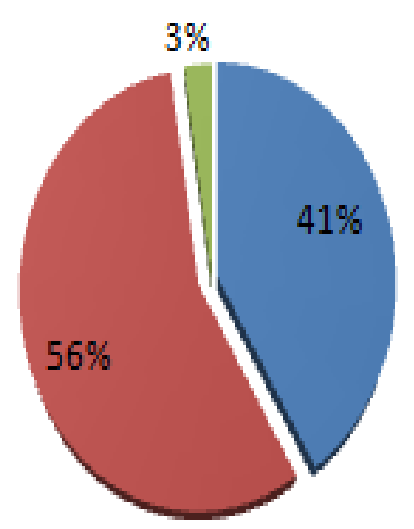

- Standoff distance (S.O.D.)

Cutting speed

Gas pressure

a) Influence on Surface roughness

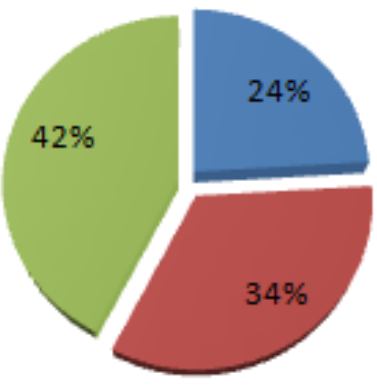

- Standoff

distance (S.O.D.)

- Cutting speed

Gas pressure

b) Influence on material removal

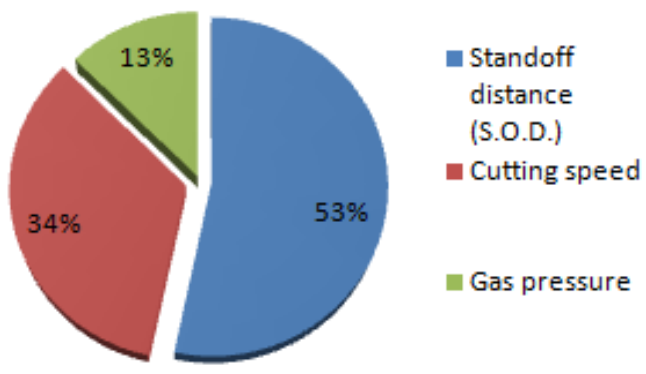

c) Influence on dimensional accuracy

Fig. 5. Effect of process parameters on LBM characteristics [44]

\section{LASER ENERGY BASED MACHINING PROCESS}

Eventually, Laser Beam Machining (LBM) is having a capability to make a complex shapes and also it is well suitable for machining of ceramics and aluminium [40-42]. Avanish Kumar Dubey et al [43] examined the affect of process variables on kerf width and deviation for Al based composites and identified that frequency and gas pressure passed for the cutting are most influencing parameter. Manjoth at al. have investigated the significance of LBM process conditions for TiB2 added $\mathrm{Al}$ alloy based composites on material removal, surface finish and dimensional accuracy [44]. Figure 5 shows the effect of process variables on LBM characteristics. 


\section{CONCLUSION}

The research work reported on non conventional machining techniques viz. AWJM, EDM, Wire-EDM, ECM, Laser energy based machining are reported in this paper. The following points were highlighted.

- AWJM process is mechanical energy based technique and the major process parameters involved in this are water pressure, traverse speed and distance.

- The process does not involve any heat addition during machining and hence there is no heat affected zone is formed.

- The most of the researchers are worked using die sinking type EDM and reported their experimental findings. The surface produced from EDM and Wire-EDM process are comparatively rough than AWJM process.

- EDM process forms heat affected zone and the micro level cracks also may induced sometimes in the sub surface of the materials.

- ECM is a cost effective and efficient techniques used for the manufacturing the hip-joint implants, turbine blades, rifle bores, micro-components.

- LBM is a thermal energy based techniques and which is a capable to make a complex shapes and also it is well suitable for machining of ceramics and aluminium.

\section{REFERENCES}

1. Müller, F. and J. Monaghan, Non-conventional machining of particle reinforced metal matrix composites. Journal of Materials Processing Technology, 2001. 118(1-3): p. 278-285.

2. Pramanik, A., Developments in the non-traditional machining of particle reinforced metal matrix composites. International Journal of Machine Tools and Manufacture, 2014. 86(0): p. 44-61.

3. Jiang-Wen, L., et al., High speed abrasive electrical discharge machining of particulate reinforced metal matrix composites. International Journal of Precision Engineering and Manufacturing, 2015. 16(7): p. 1399-1404.

4. F. Muller and J. Monaghan, "Non-conventional machining of particle reinforced metal matrix composite", International Journal of Machine Tools and Manufacture, 2000, Volume 40, pp 1351-1366.

5. S. Srinivas, N. Rameshbabu, Role of garnet and silicon carbide in abrasive waterjet of aluminum-silicon carbide particulate metal matrix 109-122.

6. S. Srinivas, N. Rameshbabu, Penetration ability of abrasive waterjet in cutting of aluminum silicon carbide particulate metal matrix composites, Int. J. Machining Science and Technology. (2012) 337-354.

7. F. Muller, J. Monaghan, Non-conventional machining of particle reinforced metal matrix composite. Int. J. of Machine Tools and Manufacture (2000) 1351-1366.

8. M. Ramulu, S.P. Raju, H. Inoue and J. Zeng, Hydro-abrasive erosion characteristic of $30 \mathrm{vol} \% \mathrm{SiC} / 6061-\mathrm{T} 6 \mathrm{Al}$ composite at shallow impact angles, Wear 166 (1993) 55-63.

9. Kumar, B.A.; Kumaresan, G. Abrasive water jet machining of aluminum-silicon carbide particulate metal matrix composites. Advanced 830-831, 83-86.

10. Hung NP, Yang IJ, Leong KW(1994) Electrical discharge machining of cast metal matrix composites. J Mater Process Technol 41:229-236.

11. Karthikeyan R, Lakshmi Narayanan PR, Naagarazan RS (1999) Mathematical modeling for electric discharge machining of aluminium-silicon carbide particulate composites. J Mater Process Technol 87:59-63.

12. Narender Singh P, Raghukandan K, Rathinasabapathi M, Pai BC (2004) Electric discharge machining of $\mathrm{Al}-10 \% \mathrm{SiCp}$ as-cast metal matrix composites. J Mater Process Technol 155-156:1653-1657.

13. Akshay D, Pradeep K, Inderdeep S (2008) Experimental investigation and optimization in EDM of $\mathrm{Al} 6063 \mathrm{SiCp}$ metal matrix composite. Int J Machin Machinab Mater 5(3/4):293-308 composites, Int. J. Applied Research in Mechanical Engineering (2011) Materials and Manufacturing Processes for Strategic Sectors 2015,

14. Yan BH, Wang CC (1999) The machining characteristics of $\mathrm{Al} 2 \mathrm{O} 3 / 6061 \mathrm{Al}$ composite using rotary electro-discharge machining with a tube electrode. J Mater Process Technol 95:222-231.

15. Wang CC, Yan BH (2000) Blind-hole drilling of Al2O3/6061Al composite using rotary electro-discharge machining. J Mater Process Technol 102:90-102

16. Kansal HK, Sehijpal S, Pradeep K (2006) An experimental study of the machining parameters in powder mixed electric discharge machining of Al-10\%SiCP metal matrix composites. Int J Machin Machinab Mater 1(4):396-411.

17. Shankar S, Sachi M, Chandra PP (2008) Effect of SiC powder suspended dielectric fluid on the surface finish of $6061 \mathrm{Al} / \mathrm{Al} 2 \mathrm{O} 3 \mathrm{P} / 20 \mathrm{p}$ composites during electric discharge machining. Int $\mathrm{J}$ Machin Machinab Mater 4(2/3):252-274.

18. Riaz Ahamed A, Asokan P, Aravindan S (2009) EDM of hybrid $\mathrm{Al}-\mathrm{SiCp}-\mathrm{B} 4 \mathrm{Cp}$ and Al-SiCp-Glassp MMCs. Int J Adv Manuf Technol 44:520-528.

19. Ho KH, Newman ST, Rahimifard S, Allen RD (2004) State of the art in wire electrical discharge machining (WEDM). Int J Mach Tools Manuf 44:1247-1259.

20. DeSilva A, Rankine DJ (1995) Electrical discharge machining of metal matrix composites. Proc. int. Symp. for Electro Machining XI, Switzerland 75-84

21. Poon, Lee TC (1993) Electrical discharge machining of particulate metal matrix composites. Proceedings of the ASME 1993 Materials Congress, Pittsburgh, PA, pp 43-50.

22. Roux Le, Wise MLH, Aspinwall DK (1993) Electric discharge machining of an aluminum alloy silicon carbide reinforced metal matrix composite. Proceedings of the 30th MATADOR Conference, Manchester, pp 247-254.

23. Rozenek M, Kozak J, Dalbrowski L, Eubkowski K (2001). Electrical discharge machining characteristics of metal matrix composites. J Mater Process Technol 109:367-370.

24. Yan BH, Tsai HC, Huang FY, Lee LC (2005) Examination of wire electrical discharge machining of Al2O3p/6061 Al composites. Int J Mach Tools Manuf 45:251-259.

25. Manna A, Bhattacharyya B (2006) Taguchi and Gauss elimination method: A dual response approach for parametric optimization of $\mathrm{CNC}$ wire cut EDM of PR AlSiC MMC. Int J Adv Manu Tech 28:67-75.

26. Muller, F.; Monaghan, J. Non-conventional machining of particle reinforced metal matrix composites. Journal of Materials Processing Technology 2001, 118 (1), 278-285.

27. Garg, R.K.; Singh, K.K.; Sachdeva, A.; Sharma, V.S.; Ojha, K.; Singh, S. Review of research work in sinking EDM and WEDM on metal matrix composite materials. The International Journal of Advanced Manufacturing Technology 2010, 50 (5-8), 611-624.

28. K. P. Rajurkar Sekar. T. Marappan, R. Experimental investigations into the influencing parameters of electrochemical machining of AISI 202, Journal of Advanced Manufacturing Systems, 7 (2008) 2, 337-43, doi:10.1142/S0219686708001486

29. DeBarr, D. A. Eand Oliver, Electro-chemical Machining, Macdonald \& Co. Ltd, 1968

30. S. K. Mukherjee, S. Kumar, P. Shrivastava, A. Kumar, Effect of valency on material removal rate in electrochemical machining of aluminium, Journal of Materials Processing Technology, 202 (2008), 398-401, doi:10.1016/j.jmatprotec.2007.09.065

31. J. A. Westley, J. Atkinson, A. Duffield, Generic aspects of tool design for electrochemical machining, Journal of Materials Processing Technology, 149 (2004), 384-392, doi:10.1016/j.jmatprotec.2004. 02.046

32. S. Dhar, R. Purohit, N. Saini, A. Sharma, G. H. Kumar, Mathematical modelling of electric discharge machining of cast Al-4Cu-6Si alloy-10 wt.\% SiCp composites, Journal of Materials Processing Technology, 194 (2007), 24-29, doi:10.1016/j.jmatprotec. 2007.03.121.

33. Chenthil Jegan Thankaraj Mariapushpam, Durairaj Ravindran, Manaharan Dev Anand. Machining Parameters Influencing In Electro Chemical Machining on AA6061 MMC. Materials and technology 50 (2016) 6, 951-960.

34. M.L.Harugade, M.V.K., N.V.Harude, Effect of electrolyte solution on material removal rate in Electro Chemical Discharge Machining. Journal of Mechanical and Civil Engineering: p. 1-8.

35. Mediliyegedara, T.K.K.R.D.S., A. K. M. Harrison, D. K. McGeough, J. A., An intelligent pulse classification system for electro-chemical discharge machining (ECDM) - a preliminary study. Journal of Materials Processing Technology, 2004. 149(1-3): p. 499-503.

36. Kulkarni, A., R. Sharan, and G.K. Lal, An experimental study of discharge mechanism in electrochemical discharge machining. International Journal of Machine Tools and Manufacture, 2002. 42(10): p. 1121-1127. 
37. J.W.Liu, T.M.Y., Z.N.Guo, Wire Electrochemical Discharge Machining of Al2O3 Particle Reinforced Aluminium alloy 6061. Material and Manufacturing Process, 2009. 24: p. 446-453.

38. Gaurav Chingal, G.S., Doordarshi Singh, A Study on Machining of A 6061/SiC (10\%) Composite by Electro Chemical Discharge Machining (ECDM) Process. International Journal of Engineering Research \& Technology (IJERT), 2013. 2(1).

39. Cronjager L, B.D., Turning of metal matrix composites. Proceedings of 2nd European Conference on Advanced Materials and Processes, 1992. 2: p. 73-80s.

40. A.Stournars, P.Stavropoulos, K.Salonitic, G.chryssolouris. CIRP Journal of Manufacturing science and technology 2(2009) 61-69

41. A.K.Dubey, V.Yadava: laser beam machining - a review. Int. J. Mach. Tool. Manuf. 48(6)(2008), P.609-628.

42. A.N.Samant, N.B.Dahotre, J.Eur.Ceran, Soc 29(6) (2009) 968

43. Avanish Kumar Dubey, VinodYadava, Journal of material processing technology. 204 (2008) $412-418$.

44. S Manjoth et al 2016 IOP Conf. Ser.: Mater. Sci. Eng. 149012013.

\section{AUTHORS PROFILE}

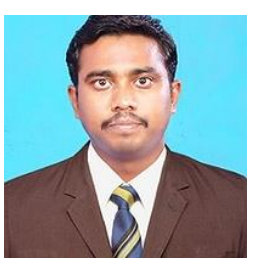

S. Suresh Kumar completed his Ph.D. degree in Mechanical Engineering from Kalasalingam Academy of Research and Education (KARE), India in 2016. He also completed Post-doc from Karadeniz Technical University, Turkey in 2018. Currently, he is doing his research in the area of non-traditional machining on metal matrix composites.

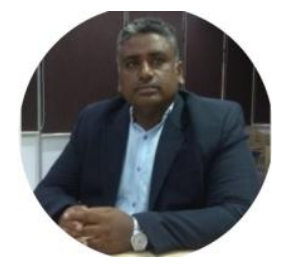

M. Uthayakumar completed his Doctoral work in the area of Precision Machining. He is actively working in the development of high strength light weight composites. His other areas of interest include processing of metal matrix, polymer matrix, ceramic matrix composite and its performance studies.

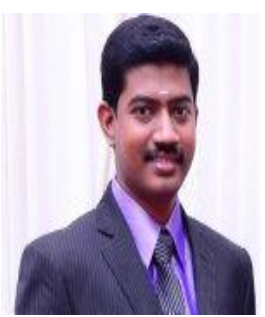

S. Thirumalai Kumaran completed his Ph.D. degree in Mechanical Engineering from Kalasalingam Academy of Research and Education (KARE), India, in 2015. After completing Ph.D., he worked as an Assistant Professor at School of Mechanical Engineering, Yeungnam University, South Korea for a period of one year. He is currently an Associate Professor at School of Automotive and Mechanical Engineering, KARE
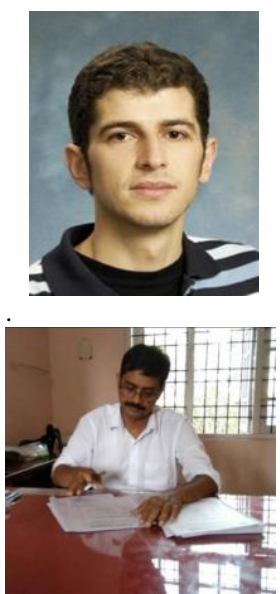

K. Vinothbabu completed his Ph.D. degree in Mechanical Engineering from Kalasalingam Academy of Research and Education (KARE), India, in 2016. He is working as professor in Sri Indu college of Engineering and Technology, Hyderabad.

Mustafa Aslan has completed his Ph.D degree in Material science from Technical University of Denmark, 2012. He is currently working as Assistant Professor in Karadeniz Technical University, Trabzon, Turkey. 